\title{
PREDICTION OF SURFACE ROUGHNESS IN HIGH SPEED MACHINING: A COMPARISON
}

\author{
Grynal D'Mello ${ }^{1}$, Srinivasa Pai $\mathbf{P}^{2}$ \\ ${ }^{I}$ Research Scholar, Department of Mechanical Engineering, NMAMIT NITTE, Karnataka, India \\ ${ }^{2}$ Professor, Department of Mechanical Engineering, NMAMIT NITTE, Karnataka, India
}

\begin{abstract}
This paper discusses the application of the Response Surface Methodology (RSM) and Artificial Intelligence (AI) based techniques namely Artificial Neural Network (ANN) and Adaptive Neuro-Fuzzy Inference System (ANFIS) for predicting surface roughness in high speed machining operations. Experiments have been carried out on CNC lathe at different speeds and feeds, with depth of cut constant. Cutting tool vibration has been measured using accelerometer mounted on the tool holder. Root Mean Square (RMS) of vibration, cutting speed and feed have been used as input parameters to develop models based on three techniques for predicting surface roughness $\left(R_{a}\right)$. A comparison has been made between these techniques.
\end{abstract}

Keywords: Response Surface Methodology, Artificial Neural Network, Adaptive Neuro-Fuzzy Inference System, Surface Roughness

\section{INTRODUCTION}

Surface roughness is one of the most important requirements in machining process. It measures the finer irregularities of the surface texture. Achieving the desired surface finish is a difficult task for the functional behavior of a part. Surface roughness influences the performance of mechanical parts and their production costs because it affects factors, such as, friction, ease of holding lubricant, electrical and thermal conductivity, geometric tolerances and more [1].

Machining is a complicated process in which many variables can directly affect the desired results. Among them, cutting tool vibration is the most critical parameter which influences the dimensional precision of the components machined, functional behaviour of the machine tools and life of the cutting tool [2]. The cutting tool vibrations are mainly influenced by cutting parameters like cutting speed, depth of cut and tool feed rate in the machining operation. Beauchamp et.al. [3] studied the effect of cutting tool vibrations on surface roughness generated by lathe dry turning of mild steel at different speed, feed and depth of cut, tool overhang and workpiece length. This analysis proved that dynamic force exist only during the built up edge range and is related to the amplitude of tool vibration at resonance and to the variation of the tool's natural frequency while cutting. Jang. et. al. [4] developed an online roughness measuring technique considering surface roughness and cutting vibrations. The cutting vibration signals of a specific frequency were superimposed on to the kinematic roughness which produced a good correlation between predicted roughness value to the experimental surface roughness value. Studies were also carried out to correlate surface roughness and cutting vibrations in turning in order to derive the mathematical models for the prediction of surface roughness based on cutting parameters and cutting tool vibrations [5]. Material used in this study is mild steel which is mainly suitable for many automotive type applications like axle and spline shaft [6].

Researchers should play an important role to model and quantify the relationship between roughness and the parameters affecting it. Most of the researchers study the effects of various factors through the execution of experiments due to the absence of accurate analytic formulation of the cause and effect relationships between various factors. Park K. S., Kim S. H. [7] reviewed the Artificial Intelligence (AI) approaches to determine the $\mathrm{CNC}$ machining parameters in manufacturing. The study showed that the use of AI would be favorable in predicting the surface roughness and the relating parameters. The most popular statistical method in the literature is the multifactorial Response Surface Methodology (RSM). Kosaraju S. et. al. [8] studied the optimal machining conditions for turning using Response Surface Methodology (RSM). RSM constructs a polynomial model which estimates the value of surface roughness. Karayel Durmus [9] analyzed the prediction and control of surface roughness in CNC lathe using artificial neural network. Neural networks are suitable for modeling various manufacturing functions due to their ability to learn complex non - linear and multivariable relationships between process parameters. Reddy B. et. al. [10] worked on the development of surface roughness prediction model for machining of aluminium alloys using Adaptive neuro-fuzzy inference system (ANFIS). ANFIS is 
the latest artificial intelligence tool used for the prediction of surface roughness and the results when compared with RSM were better.

This paper investigates surface roughness modeling in high speed turning operations. Cutting experiments have been carried out at different speeds and feeds with a constant depth of cut. Cutting tool vibrations have been measured online using accelerometer mounted on the tool holder and surface roughness measured offline using a conventional stylus type instrument. The cutting condition and vibration parameter have been used to predict surface roughness using three different modeling techniques. A comparison is made between these techniques.

\section{EXPERIMENTAL SETUP AND DETAILS}

\subsection{Machine and Instruments Used}

The experimental setup is shown in Fig-1. The turning experiments were carried out under dry machining conditions on a CNC turning centre HMT Stallion 1000 make which has a maximum spindle speed of $3500 \mathrm{rpm}$. The cutting tool vibrations during the machining trials were measured online using an accelerometer (KD37V/01) mounted on the tool holder in the feed direction. The accelerometer signals have been sent to the DAQ system which processes the raw vibration signals using LAB VIEW software.

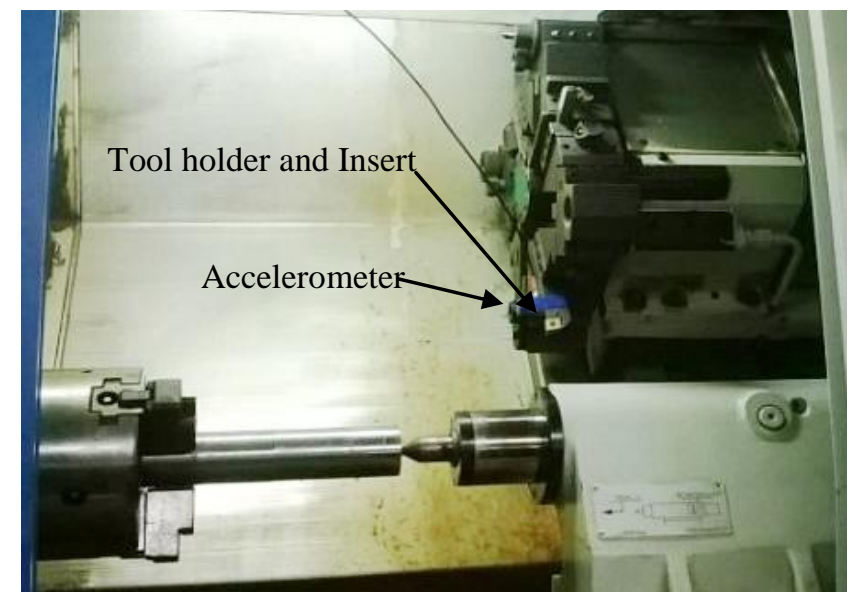

Fig-1: Experimental setup

\subsection{Work Material}

The specimen was cylindrical bar of mild steel with $50 \mathrm{~mm}$ diameter and $150 \mathrm{~mm}$ length. The discontinuous or unexpected hardening distribution on specimens can appear due to the production process. Therefore in order to remove the outer layer, before the experiments, the specimens were turned to $5 \mathrm{~mm}$ cutting depth. Final dimensions were $45 \mathrm{~mm}$ diameter and $120 \mathrm{~mm}$ cutting length.

\subsection{Insert and Tool Holder Details}

Tool holder used for turning operation is WIDAX tool holder PCLNL $2020 \mathrm{~K} 12$ and the tool insert was a coated carbide cutting tool CNMG 120404. Twenty seven experiments have been carried out for different cutting speeds, feeds and constant depth of cut. The turning experiments were carried out for $40 \mathrm{~mm}$ length each considered one pass. Depth of cut was kept constant varying the speed and feed.

\subsection{Surface Roughness Measurement}

The instrument used to measure surface roughness was Taylor Hobson Form Taly Surf 50. Surface roughness readings were recorded at three locations on the work piece and the average value was used for analysis. The measurement has been carried out offline.

\section{PREDICTION USING RESPONSE SURFACE METHODOLOGY (RSM)}

\subsection{Introduction}

RSM is a combination of mathematical theory and statistical techniques, and useful for modeling and analyzing problems in which a response of interest is influenced by several variables and the objective is to optimize this response. RSM also quantifies the relationship between the controllable input parameters and the obtained response surfaces [11].

In this study, RSM has been employed for modeling and analyzing the surface roughness in terms of vibration parameters and cutting conditions. The relationship between the surface roughness and the independent input variables has been obtained in terms of a first order model of the form

$$
Y=b_{0}+\sum_{i=1}^{k} b_{i} X_{i}
$$

Where $\mathrm{Y}$ is the predicted response; $\mathrm{X}$ is the input variable that influences the response variable, $b_{o}$, the intercept and $b_{i}$ is the $\mathrm{i}^{\text {th }}$ linear coefficient.

\subsubsection{Experimental Analysis}

The contributions and effects of cutting speed $\left(\mathrm{X}_{1}, \mathrm{rpm}\right)$, feed rate $\left(\mathrm{X}_{2}, \mathrm{~mm} / \mathrm{rev}\right)$ and Root Mean Square (RMS) of vibration $\left(\mathrm{X}_{3}\right)$ on surface roughness $\left(\mathrm{R}_{\mathrm{a}}, \mu \mathrm{m}\right)$ has been studied by maintaining them in three levels shown in Table-1 by a $(3$ factor*3 level) experimental design encompassing twenty seven experimental runs. The surface roughness $\left(R_{a}\right)$ has been determined as the response (dependent variable). The regression and the graphical analysis of the data output obtained from the experimental runs has been performed by STATISTICA 8.0 software [12]. 


\subsubsection{Validation of the Model}

The mathematical model generated using RSM has been validated by performing four experiments which contained random combination of the factors within the range of experimentation shown in Table-1. The experimental output has been compared to the values predicted by the first order polynomial equation to evaluate the fitness of the model.

Table-1: Maximum and minimum levels of variables used in the experimental design

\begin{tabular}{|l|l|l|l|}
\hline \multirow{2}{*}{ Factors } & \multicolumn{3}{|l|}{ Levels } \\
\cline { 2 - 4 } & -1 & 0 & 1 \\
\hline $\mathrm{X} 1$ & 730 & 790 & 860 \\
\hline $\mathrm{X} 2$ & 0.15 & 0.2 & 0.25 \\
\hline $\mathrm{X} 3$ & 0.0047 & 0.0143 & 0.0239 \\
\hline
\end{tabular}

\subsection{Results and Discussions}

\subsubsection{Prediction of Surface Roughness by First Order}

\section{Polynomial Model}

The surface roughness values from experiments and that predicted by the first order model are given in Table-2. The first order model developed by regression analysis is

$$
\mathrm{R}_{\mathrm{a}}=0.0053-0.00026 \mathrm{X}_{1}+7.73 \mathrm{X}_{2}+34.356 \mathrm{X}_{3}
$$

In order to test the adequacy and significance of the model, ANOVA was performed (Table 4). It has been observed that feed rate and RMS are found to have a direct effect on $R_{a}$ $(p<0.05)$ whereas the effect of cutting speed has been found to be insignificant. Similar results have been observed by Noordin et. al. [11] when turning AISI 1045 steel.

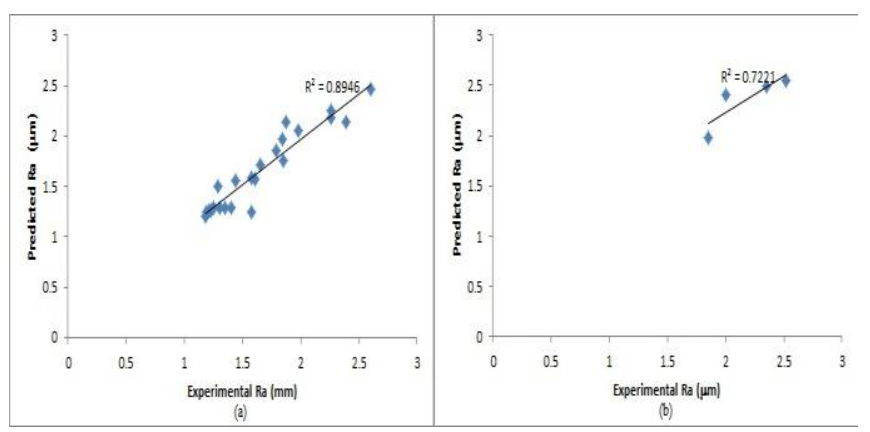

Fig-2: Predicted vs Experimental values of $\mathrm{R}_{\mathrm{a}}$ for (a) training and (b) test data

The coefficient of regression $\left(\mathrm{R}^{2}\right)$ was found to be 0.8946 which indicates that the model has been able to explain $89.4 \%$ of variation for training data and $72.21 \%$ for test data as shown in Fig-2. The predicted values for test data are given in Table-5.

\subsubsection{Response Surface Profiles}

Response surface plots, as a function of two variables at a time, maintaining the third variable at the center of its coded value is helpful in studying the main and interaction effects of the variables. A simultaneous increase in RMS with the feed resulted in the increase of the surface roughness as shown in Fig-3.

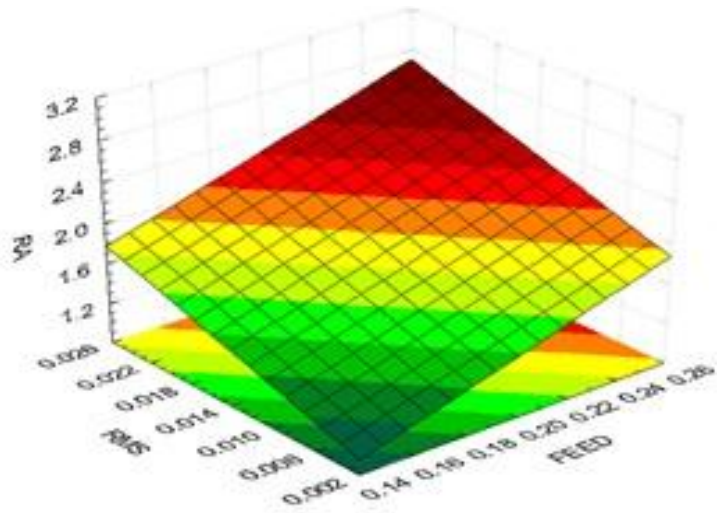

Fig-3: Influence of feed and RMS on $\mathrm{R}_{\mathrm{a}}$

\section{PREDICTION USING ARTIFICIAL NEURAL NETWORK (ANN)}

\subsection{Introduction}

Neural networks are widely used artificial intelligence tools which are suitable for modeling various manufacturing functions due to their ability to learn complex non-linear and multivariable relationships between process parameters [9]. In this study, artificial neural networks have been used to get the predicted values of surface roughness in turning operation.

A feed forward multi-layered neural network has been developed using the experimental data, where the input parameters are speed, feed and RMS value of vibration and surface roughness $R_{a}$ value is the output parameter. MATLAB $\mathrm{R} 2012 \mathrm{a}$ version has been used to develop the multi-layer perceptron (MLP) model by using neural network toolbox. MLP is a feed forward network consisting of neurons in an input layer, one or more hidden layers and an output layer. Different layers have interconnections such that each neuron in one layer is connected to all neurons in the next layer. Processing of the information is done by the hidden neurons and output layer. Neural network can be trained to perform the functions by adjusting the values of the connections between the neurons. Individual input is given and the network output is compared to the target output. Error is calculated between the actual values and the predicted values by the neural network [9]. 


\subsection{Results and Discussions}

The architecture consists of three layers: an input layer, a hidden layer and an output layer as shown in Fig-4. Number of neurons in the hidden layer has to be selected however there is no specific rule for the selection and hence is done by trial and error [13]. The training of the network has been done using twenty three experimental values as given in the table 3 . Various algorithms available in the neural network toolbox have been studied and Fletcher-Powell Conjugate Gradient (traincgf) gave the best training results when compared to other algorithms. The numbers of neurons were varied from 5 to 20 , learning rate of 0.01 and target of 0.001 has been selected. For 20 hidden neurons optimum results were obtained in terms of prediction accuracy. The predicted values for test data are given in Table-5.

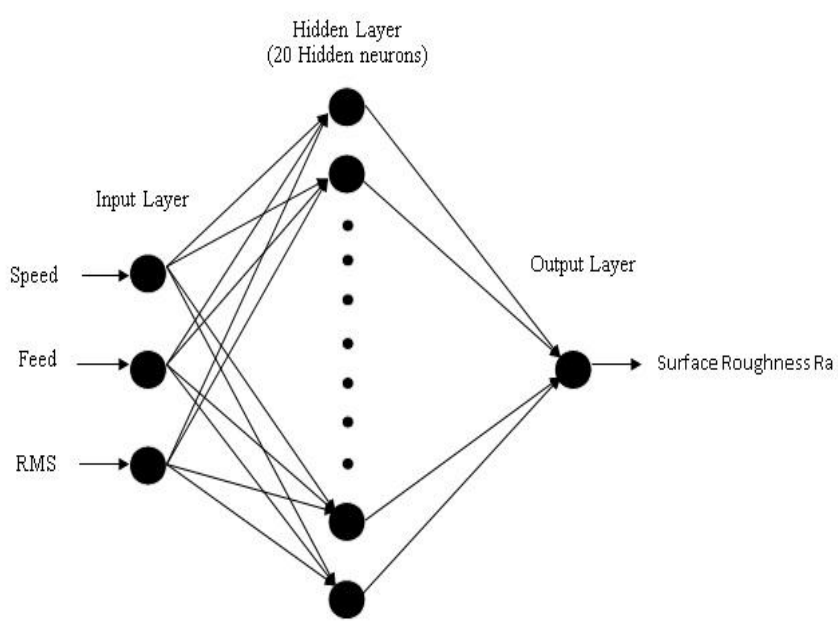

Fig-4: Structure of MLP network used

Fig-5 shows predicted vs experimental values. $\mathrm{R}^{2}$ values of 0.9161 for training data and 0.7644 for test data has been obtained respectively.
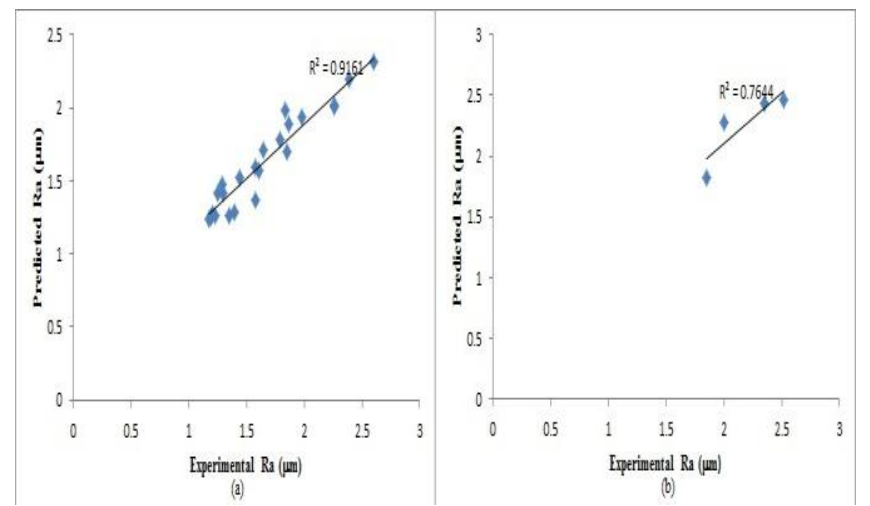

Fig-5: Predicted vs Experimental values of $\mathrm{R}_{\mathrm{a}}$ for (a) Training and (b) test data

\section{PREDICTION USING ADAPTIVE NEURO- FUZZY INFERENCE SYSTEM (ANFIS)}

\subsection{Introduction}

The fuzzy inference system (FIS) is a technique which effectively identifies and controls the complex linear systems. By using a hybrid learning procedure, ANFIS can construct an input-output model based on both human-knowledge as fuzzy which rules and gives stipulated input-output data pairs for neural networks training [14]. The ANFIS toolbox constructs a fuzzy inference system (FIS) whose membership function parameters are adjusted using either a back propagation algorithm alone, or in combination with a least squares method [15].

The general ANFIS structure is shown in Fig-6. ANFIS uses five network layers to perform the following fuzzy inference steps. (i) Input fuzzification, (ii) fuzzy set database construction, (iii) fuzzy rule base construction, (iv) decision making, and (v) output defuzzification.

Layer 1: Calculate Membership Value for Premise Parameter Layer 2: Firing Strengths of Rules

Layer 3: Normalize Firing Strengths

Layer 4: Consequent Parameters

Layer 5: Overall Output

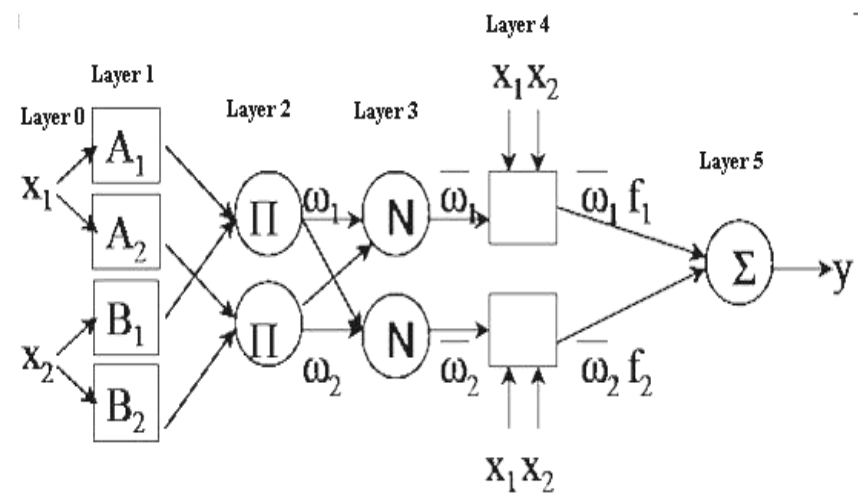

Fig-6: Basic ANFIS architecture

ANFIS requires a set of training data for desired input/output pair depicting the target system to be modeled [10]. 


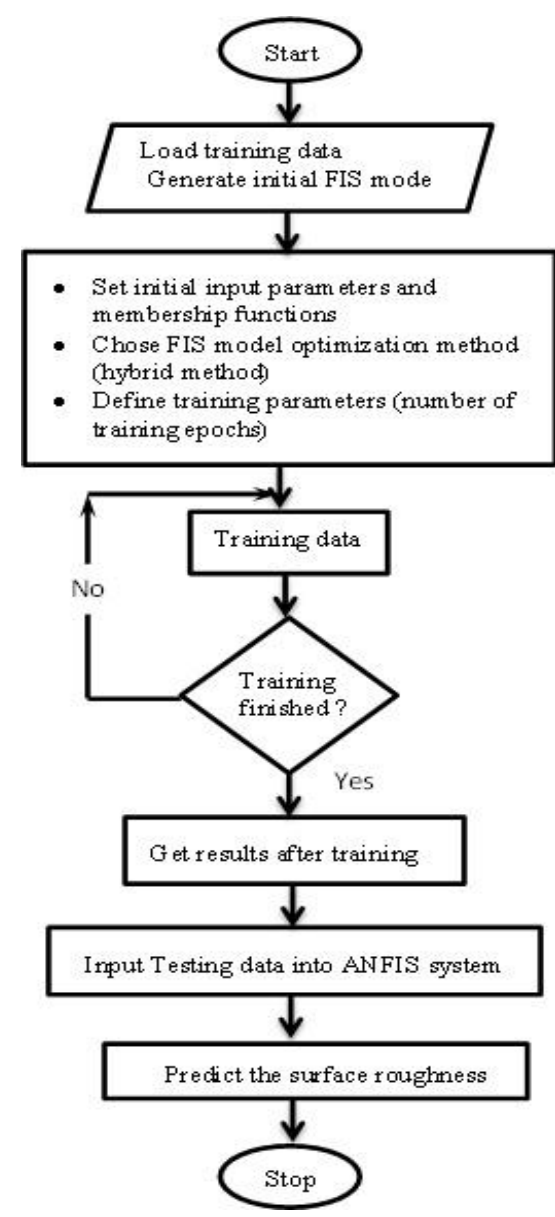

Fig-7: Flow chart for ANFIS

ANFIS adaptively maps the inputs to the outputs (y) through MFs, the rule base and the related parameters emulating the given training data set. The flow chart of ANFIS process used is shown in Fig-7. It starts with initial MFs, in terms of type and number, and the rule base that can be designed intuitively. ANFIS applies a hybrid learning method for updating the FIS parameters. It utilizes the gradient descent approach to finetune the premise parameters that define MFs. It applies the least-squares method to identify the consequent parameters that define the coefficients of each output equation in the Sugeno-type fuzzy rule base. The training process continues till the desired number of training steps (epochs). In addition to the training data, the test data are also used for checking the generalization capability of FIS.

\subsection{Results and Discussions}

The ANFIS model has been developed as a function of machining parameters using twenty three training data presented in Table-3. Fuzzy logic toolbox has been used to train the ANFIS model and obtain the results using MATLAB R2012a. Three inputs and one output have been considered for developing the ANFIS model. Four test data have been considered in order to predict the value of surface roughness to check the accuracy of the developed model. ANFIS learning scenario for predicting surface roughness has been as follows: number of nodes 82 and number of linear parameters 110. The number of fuzzy rules has been 27 for the output parameter. The predicted values obtained by ANFIS for training data are given in Table- 3 and the predicted values of test data are given in Table-5.

Fig-8 shows predicted vs experimental values and corresponding $\mathrm{R}^{2}$ values is 0.9995 for training data and 0.9024 for test data respectively.

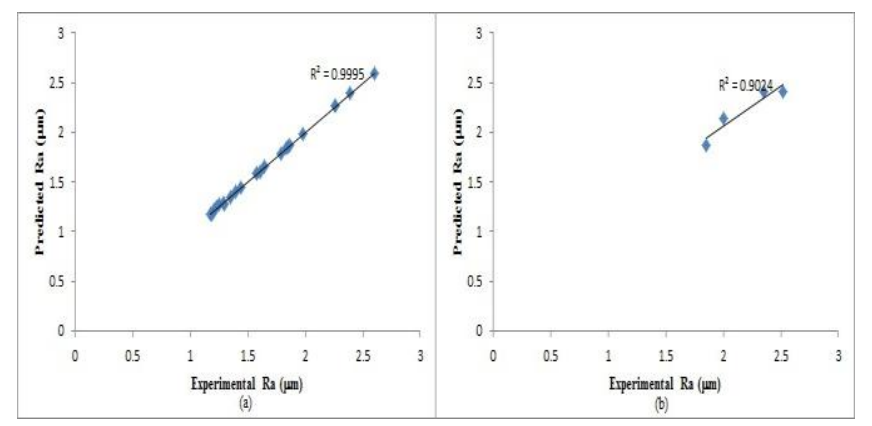

Fig-8: Predicted vs Experimental values of $\mathrm{R}_{\mathrm{a}}$ for (a) Training and (b) test data

\section{COMPARISON OF RESULTS}

In this study, ANFIS provided better prediction capabilities than ANN and RSM. Similar results have been observed by Hari Krishna S. et. al. [16] when ANFIS was compared with ANN. This is because it is a hybrid method based on fuzzy logic and artificial neural network. Table-2 shows the comparative results of the three techniques.

Table-2: Comparison of optimization techniques

\begin{tabular}{|c|c|c|}
\hline Techniques & $\begin{array}{c}\mathbf{R}^{\mathbf{2}} \\
\text { (Training data) }\end{array}$ & $\begin{array}{c}\mathbf{R}^{\mathbf{2}} \\
\text { (Test data) }\end{array}$ \\
\hline RSM & 0.8964 & 0.7221 \\
\hline ANN & 0.9161 & 0.7644 \\
\hline ANFIS & 0.9995 & 0.9024 \\
\hline
\end{tabular}

ANFIS prediction of surface roughness is better than ANN and RSM with a higher coefficient of regression of more than 0.9 for both training and test data.

\section{CONCLUSIONS}

In this paper, an effort has been made to compare three modeling techniques to predict the surface roughness during high speed turning operations on mild steel. Cutting speed, feed and RMS value of cutting vibrations has been used as the input parameters and $R_{a}$ is the output parameter. The evaluation has been done on a statistical basis using $\mathrm{R}^{2}$ (coefficient of regression) values and not on the basis of 
prediction accuracy, which is based on error. The reason being the number of experimental data used in this effort is limited.

Accordingly the following observations can be made:

i. ANFIS has been found to be an effective modeling technique in predicting surface roughness with a $\mathrm{R}^{2}$ value of more than 0.9 when compared to other two techniques for both training and test data. ii. ANN model has not been very effective in predicting the surface roughness

iii. $\quad$ RSM can be used as an effective tool in evaluating the influence of different dependent variables namely cutting speed, feed and cutting tool vibration on the independent variable namely surface roughness.

Table-3: Predicted results for training data for the three modeling techniques

\begin{tabular}{|c|c|c|c|c|c|c|c|}
\hline Sl. No. & $\begin{array}{l}\text { Speed } \\
(\mathrm{rpm})\end{array}$ & $\begin{array}{l}\text { Feed } \\
(\mathrm{mm} / \mathrm{rev})\end{array}$ & $\begin{array}{l}\text { RMS of } \\
\text { vibration }\end{array}$ & $\begin{array}{l}\text { Surface } \\
\text { Roughness } \\
\mathrm{R}_{\mathrm{a}}(\mu \mathrm{m})\end{array}$ & $\begin{array}{l}\text { RSM } \\
\text { predicted } \\
\mathrm{R}_{\mathrm{a}}(\mu \mathrm{m})\end{array}$ & $\begin{array}{l}\text { ANN } \\
\text { predicted } \\
\mathrm{R}_{\mathrm{a}}(\mu \mathrm{m})\end{array}$ & $\begin{array}{l}\text { ANFIS } \\
\text { predicted } \\
\mathrm{R}_{\mathrm{a}}(\mu \mathrm{m})\end{array}$ \\
\hline 1. & 730 & 0.15 & 0.0088 & 1.35 & 1.283 & 1.267631 & 1.34377 \\
\hline 2. & 730 & 0.15 & 0.0084 & 1.23 & 1.263 & 1.259098 & 1.244998 \\
\hline 3. & 730 & 0.15 & 0.0079 & 1.19 & 1.245 & 1.248733 & 1.181161 \\
\hline 4. & 730 & 0.2 & 0.0061 & 1.61 & 1.57 & 1.574556 & 1.597725 \\
\hline 5. & 730 & 0.2 & 0.0106 & 1.65 & 1.72 & 1.715908 & 1.649875 \\
\hline 6. & 730 & 0.2 & 0.0066 & 1.58 & 1.587 & 1.589287 & 1.592217 \\
\hline 7. & 730 & 0.25 & 0.0113 & 2.39 & 2.135 & 2.192885 & 2.390022 \\
\hline 8. & 790 & 0.15 & 0.0095 & 1.4 & 1.285 & 1.291546 & 1.398437 \\
\hline 9. & 790 & 0.15 & 0.0089 & 1.21 & 1.264 & 1.275859 & 1.212994 \\
\hline 10. & 790 & 0.15 & 0.0072 & 1.18 & 1.206 & 1.23364 & 1.178484 \\
\hline 11. & 790 & 0.2 & 0.0147 & 1.79 & 1.85 & 1.782719 & 1.789943 \\
\hline 12. & 790 & 0.2 & 0.0063 & 1.44 & 1.56 & 1.519387 & 1.440092 \\
\hline 13. & 790 & 0.2 & 0.0047 & 1.29 & 1.506 & 1.46953 & 1.290024 \\
\hline 14. & 790 & 0.25 & 0.007 & 1.84 & 1.97 & 1.984528 & 1.839506 \\
\hline 15. & 860 & 0.15 & 0.0104 & 1.25 & 1.29 & 1.419544 & 1.274939 \\
\hline 16. & 860 & 0.15 & 0.0104 & 1.3 & 1.29 & 1.419544 & 1.274939 \\
\hline 17. & 860 & 0.15 & 0.0088 & 1.58 & 1.242 & 1.374102 & 1.58019 \\
\hline 18. & 860 & 0.2 & 0.0123 & 1.85 & 1.75 & 1.704274 & 1.849752 \\
\hline 19. & 860 & 0.25 & 0.0145 & 2.26 & 2.25 & 2.014218 & 2.260102 \\
\hline 20. & 860 & 0.25 & 0.0137 & 2.26 & 2.184 & 2.002212 & 2.26 \\
\hline 21. & 860 & 0.25 & 0.0098 & 1.98 & 2.05 & 1.934668 & 1.980052 \\
\hline 22. & 790 & 0.25 & 0.0214 & 2.6 & 2.46 & 2.309079 & 2.599336 \\
\hline 23. & 860 & 0.2 & 0.0239 & 1.87 & 2.14 & 1.887566 & 1.870042 \\
\hline
\end{tabular}

Table-4: The significance of cutting speed, feed and RMS of vibration on surface roughness

\begin{tabular}{|c|c|c|c|c|c|c|}
\hline Variables & SS & df & MS & F & $\mathbf{p}^{*}$ & Significance \\
\hline $\mathrm{X}_{1}$ & 0.00362 & 1 & 0.00362 & 0.16549 & 0.6887 & Insignificant \\
\hline $\mathrm{X}_{2}$ & 1.91528 & 1 & 1.91528 & 87.6037 & $1.5 \mathrm{E}-08$ & Significant \\
\hline $\mathrm{X}_{3}$ & 0.42287 & 1 & 0.42287 & 19.3418 & 0.00031 & Significant \\
\hline Error & 0.4154 & 19 & 0.02186 & & & \\
\hline Total SS & 3.86892 & 22 & & & & \\
\hline
\end{tabular}

${ }^{*} p<0.05$ indicates significance at $95 \%$ confidence level 
Table-5: Prediction results for test data for the three modeling techniques

\begin{tabular}{|c|c|c|c|c|c|c|c|}
\hline Sl. No. & $\begin{array}{l}\text { Speed } \\
(\mathrm{rpm})\end{array}$ & $\begin{array}{l}\text { Feed } \\
(\mathrm{mm} / \mathrm{rev})\end{array}$ & $\begin{array}{l}\text { RMS of } \\
\text { vibration }\end{array}$ & $\begin{array}{l}\text { Surface } \\
\text { Roughness } \\
\mathrm{R}_{\mathrm{a}}(\mu \mathrm{m})\end{array}$ & $\begin{array}{l}\text { RSM } \\
\text { predicted } \\
\mathrm{R}_{\mathrm{a}}(\mu \mathrm{m})\end{array}$ & $\begin{array}{l}\text { ANN } \\
\text { predicted } \\
\mathrm{R}_{\mathrm{a}}(\mu \mathrm{m})\end{array}$ & $\begin{array}{l}\text { ANFIS } \\
\text { predicted } \\
\mathrm{R}_{\mathrm{a}}(\mu \mathrm{m})\end{array}$ \\
\hline 1. & 860 & 0.2 & 0.0192 & 1.85 & 1.98 & 1.830222 & 1.8702 \\
\hline 2. & 790 & 0.25 & 0.0198 & 2 & 2.41 & 2.284779 & 2.1331 \\
\hline 3. & 730 & 0.25 & 0.0234 & 2.52 & 2.55 & 2.468482 & 2.411 \\
\hline 4. & 730 & 0.25 & 0.0216 & 2.35 & 2.49 & 2.439302 & 2.4136 \\
\hline
\end{tabular}

\section{REFERENCES}

[1]. Feng, C.-X.,Wang, X.-F., "Surface roughness predictive modeling: neural networks versus regression", IIE Trans. Vol.35, 2003, pp 11-27.

[2]. Abuthakeer S. S., Mohan P. V. and Mohan Kumar G., "Prediction and Control of Cutting Tool Vibration in CNC Lathe with ANOVA and ANN", International Journal of Lean Thinking, Vol.2, No. 1, June 2011.

[3]. M. Thomas, Y. Beauchamp, A. Y. Youssef, J. Masounave, "Effect of tool vibration on surface roughness during lathe dry turning process", Comput. Ind. Eng. Vol.31, No. 3-4, 1996, pp 637-644.

[4]. D. Y. Jang, Y. G. Kim, A. Hsiao,"Study of the correlation between surface roughness and cutting vibrations

to develop an online roughness measuring technique in hard turning”, Int. J. Mach. Tools Manuf., Vol.36, No.4, 1996, pp 453-464

[5]. Abouelatta O. B. and Madl J.,"Surface Roughness prediction based on cutting parameters and tool vibrations in turning", Journal of Materials Processing Technology, Vol.118, 2001, pp 269-277

[6]. E. Oberg, R.E. Green, Machinery's Handbook, 25th ed., Industrial Press Inc., New York, 1996.

[7]. Park K. S., Kim S. H.," Artificial intelligence approaches to determination of $\mathrm{CNC}$ machining parameters in manufacturing: a review", Artificial Intelligence in Engineering, Vol.12, No. 1-2, January-April 1998, pp $127-$ 134.

[8]. Kosaraju S., Anne V. G., "Optimal machining conditions for turning Ti-6Al-4V using response surface methodology", Adv. Manuf., Vol.1, 2013, pp 329-339.

[9]. Karayel Durmus, "Prediction and control of surface roughness in CNC lathe using artificial neural network", Journal of materials processing technology, Vol.209, 2009, pp 3125-3137.

[10]. Reddy B. Sidda, Kumar J. Suresh, Kumar Reddy K. Vijaya, "Prediction of Surface Roughness in Turning Using Adaptive Neuro-Fuzzy Inference System", Jordan Journal of Mechanical and Industrial Engineering, Vol.3, No.4, December 2009, pp $252-259$.

[11]. Noordin M.Y.,Venkatesh V.C., Sharif S., Elting S., Abdullah A., "Application of response surface methodology in describing the performance of coated carbide tools when turning AISI 1045 steel”, Journal of Materials Processing Technology, Vol.145, 2004, pp 46-58.

[12]. Statsoft, Statistics For Windows, Statsoft, Tulsa, Okla, USA, 1999.

[13]. Pala, M., Caglar, N., Elmas, M., Cevik, A., Saribiyik, M., "Dynamic soil structure interaction analysis of neural network", Construction and Building Materials, Vol.22, No.3, pp 330-342.

[14]. Samhouri S. M., surgenor B.W., "Surface roughness in grinding: on-line prediction with adaptive neuro-fuzzy inference system". Transactions of NAMRI/SME, Vol. 33, 2005, pp 57-64.

[15]. Hari Krishna S., Satyanarayana K., Bapi Raju K., "Surface roughness prediction model using ANN \& ANFIS", International Journal of Advanced Engineering Research and Studies, Vol. 1, No. 1, October-December 2011, pp 102-113.

[16]. Hari Krishna S, Satyanarayana K, Bapi Raju K,"Surface roughness prediction model using ANN \& ANFIS", International Journal of Advanced Engineering Research and Studies, Vol. 1, No. 1, October-December 2011, pp 102-113.

\section{BIOGRAPHIES}

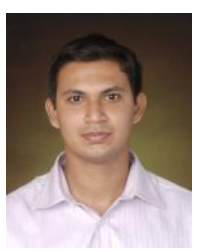

Mr. Grynal D'Mello is currently working as Assistant Professor in the Department of Mechanical Engineering in NMAMIT, Nitte. $\mathrm{He}$ has three years of teaching experience. $\mathrm{He}$ is currently pursuing his $\mathrm{PhD}$ in the area of surface roughness modeling in Ti based alloys.

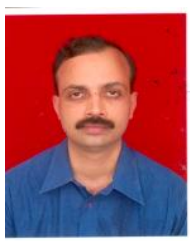

Dr. Srinivasa Pai P. is currently working as Professor in the department of Mechanical Engineering in NMAMIT, Nitte. He has 18 years of teaching and research experience. His research areas include tool condition monitoring, artificial neural networks, condition monitoring of bearings and gears and surface roughness modeling. 